Article

\title{
Enhanced Plant Restoration in Open-Pit Mines Using Maize Straw and Ultrasonically Pre-Treated Coal Fly Ash
}

\author{
Xiang Lu ${ }^{1,2,3}$, Wei Zhou ${ }^{1,2,3}$, Chongchong Qi ${ }^{4,5, * \mathbb{D}}$ and Meng Yang 1 \\ 1 School of Mines, China University of Mining and Technology, Xuzhou 221116, China; \\ Xianglu@cumt.edu.cn (X.L.); zhwcumt@cumt.edu.cn (W.Z.); TB16020070A3@cumt.edu.cn (M.Y.) \\ 2 State Key Laboratory of Coal Resources and Safe Mining, China University of Mining and Technology, \\ Xuzhou 221116, China \\ 3 High-Tech Research Center for Open Pit Mines, China University of Mining and Technology, \\ Xuzhou 221116, China \\ 4 School of Resources and Safety Engineering, Central South University, Changsha 410083, China \\ 5 School of Civil, Environmental and Mining Engineering, University of Western Australia, \\ Perth 6009, Australia \\ * Correspondence: chongchong.qi@csu.edu.cn or chongchong.qi@research.uwa.edu.au
}

Received: 12 September 2020; Accepted: 6 November 2020; Published: 10 November 2020

\begin{abstract}
The rehabilitation of the post-mining landscape is one of the intractable bottlenecks faced by the mining industry. Though plant restoration has been regarded as an efficient way, its application is often restricted by the physicochemical properties of the soil, i.e., macronutrient deficiencies. In this work, a novel plant restoration method was proposed that employs maize straw and ultrasonically pre-treated coal fly ash (UCFA) for soil amelioration. Seed germination experiments were performed to investigate the effect of maize straw leachates (MSLs) on the growth of maize, alfalfa, and soybean. Then, the influence of MSLs and UCFA on the physiological attributes, chlorophyll, and trace element concentrations of maize was studied by plant growth experiments. Our results show that: (i) the MSLs concentration had a significant effect on the plant growth and the optimum concentration was $20 \%$; (ii) considering the physiological attributes of maize plants, MSLs and UCFA benefited its growth in most cases. The UCFA proportion should be less than $20 \mathrm{v}$ \% for optimum performance; (iii) the mixture of MSLs and UCFA could generally increase the chlorophyll and decrease trace element concentrations; and (iv) the optimum proportion was found to be soil:UCFA:MSLs = 70:20:10 and soil:UCFA:MSLs $=60: 20: 20$, which achieved satisfactory performance during engineering applications.
\end{abstract}

Keywords: open-pit mine; rehabilitation; plant restoration; maize straw; coal fly ash

\section{Introduction}

Open-pit coal mining has long been criticized for its potential to cause severe long-term land degradation. During mining practice, a large amount of mine spoil will be dumped to the adjacent land, resulting in stockpiles, then the formation of spoil overburden dumps [1]. With greater public awareness of these dumps on the environment and public health, i.e., soil contamination, the rehabilitation of overburden dumps has been one of the most important issues encountered by the mining industry [2]. The main objective of such rehabilitations is to restore a disturbed ecosystem so it is similar to the pre-existing ecosystem, both in structure and function, or maintain a self-sustaining ecosystem similar to the adjacent unmined land [3-5]. In some developed nations, like Australia, the rehabilitation of mined land is now a legislative requirement for the sustainable development and cleaner production of the mining industry [6-12]. 
Direct plant restoration on spoil overburden dumps is often infeasible due to the physicochemical properties of soil, including but not limited to unsuitable $\mathrm{pH}$, macronutrient deficiencies, low waterholding capacity, and potential trace metal contamination [13,14]. Amendments might be needed to create conditions that are more favorable for plant growth [15]. Many studies have thus been conducted to investigate the feasibility of different materials for soil amelioration, among which coal fly ash (CFA) and crop straw have attracted much interest from both academia and industry [16].

Accounting for a major proportion (around 85-95\%) of the total ash generated during the coal combustion in thermal power plants, CFA is produced at a rate of 5-20 wt.\% of the feed coal [17-19]. Similar to open-pit dumps, CFA could pose severe environmental hazards if not disposed of properly [20-22]. Many efforts have been devoted to the recycling of CFA, such as using CFA in concrete production, road base construction, and zeolite synthesis [23]. Considering the physicochemical properties of CFA, i.e., clay-sized particles and favorable $\mathrm{pH}$, recycling CFA for soil amelioration has been intensively investigated $[24,25]$. It has been found that CFA could improve the soil texture, increase the water retention, reduce soil bulk density, and supply some useful nutrients, such as P, S, K, Ca, and Zn [20,26]. However, the major obstacle of utilizing CFA for soil amelioration lies in the interior toxic trace metals, which require pre-treatment (i.e., non-dusty treatment and ultrasonic treatment) before its application.

The co-utilization of CFA with other organic and inorganic materials for soil amelioration has been proven to be more advantageous in enhancing nutrient availability, improving soil health, and buffering soil $\mathrm{pH}$, to name a few [20]. Lime, gypsum, sewage sludge, poultry and animal manure, crop straw, and composts have been investigated for their feasibilities of co-application with CFA [27]. Among all co-disposal materials of CFA, crop straw has attracted increasing attention [28]. For one thing, a large amount of crop straw is produced every year and a proportion of crop straw (around 25\%) has already been incorporated into the soil [16]. For another, many studies have concluded that the incorporation of crop straw into the soil could reduce heavy metals toxicity, improve soil health and enhance soil organic matter $[29,30]$. However, little research has been done about the influence of maize straw on soil quality and/or plant yield [31].

It is evident that although many studies have been conducted on the rehabilitation of spoil overburden dumps using various types of amendments, only limited information is available regarding the amelioration efficiency of pre-treated CFA and maize straw. Therefore, the major objectives of this study are to: (1) evaluate the effect of maize straw leachate on plant growth characteristics; (2) evaluate the effect of co-amendments, including ultrasonic pre-treated CFA and maize straw leachate, on physiological attributes of plants; (3) evaluate the effect of co-amendments on chlorophyll and trace element concentration of plants; and (4) present an industrial application of the dumps' restoration using ultrasonic pre-treated CFA and maize straw leachate.

\section{Materials and Methods}

\subsection{Materials}

\subsubsection{Soil Sample Collection and Characteristics of Experimental Soil}

The refuse dump soil used in the experiment was sampled from Baorixile open-pit mine in Inner Mongolia, China ( $119^{\circ} 53^{\prime} 37^{\prime \prime}-119^{\circ} 58^{\prime} 07^{\prime \prime} \mathrm{E}$ and $\left.49^{\circ} 18^{\prime} 45^{\prime \prime}-49^{\circ} 29^{\prime} 30^{\prime \prime} \mathrm{N}\right)$. The location of the Baorixile open-pit mine is illustrated in Figure 1. The altitude of this area is between $601.9-724.9 \mathrm{~m}$ with a climate of temperate continental monsoon. The average annual temperature is $-2.6-2.2{ }^{\circ} \mathrm{C}$ (measured over ten years). The average annual rainfall is $315.0 \mathrm{~mm}$ and, in contrast, the average annual evaporation is $1344.8 \mathrm{~mm}$. Sampling was conducted at the sampling point in the inner dump of the open-pit mine. Soil materials with different depth were sampled to maintain its representativeness during lab experiments. Soil sampling was performed in spring, and the sampled soil was transferred to the Advanced Analysis and Computation Center at China University of Mining and Technology for laboratory testing. The sampled refuse dump soil was first dried at room temperature and 
passed through a sieve with a mesh size of $2 \mathrm{~mm}$. After that, the physicochemical properties of soil were determined.

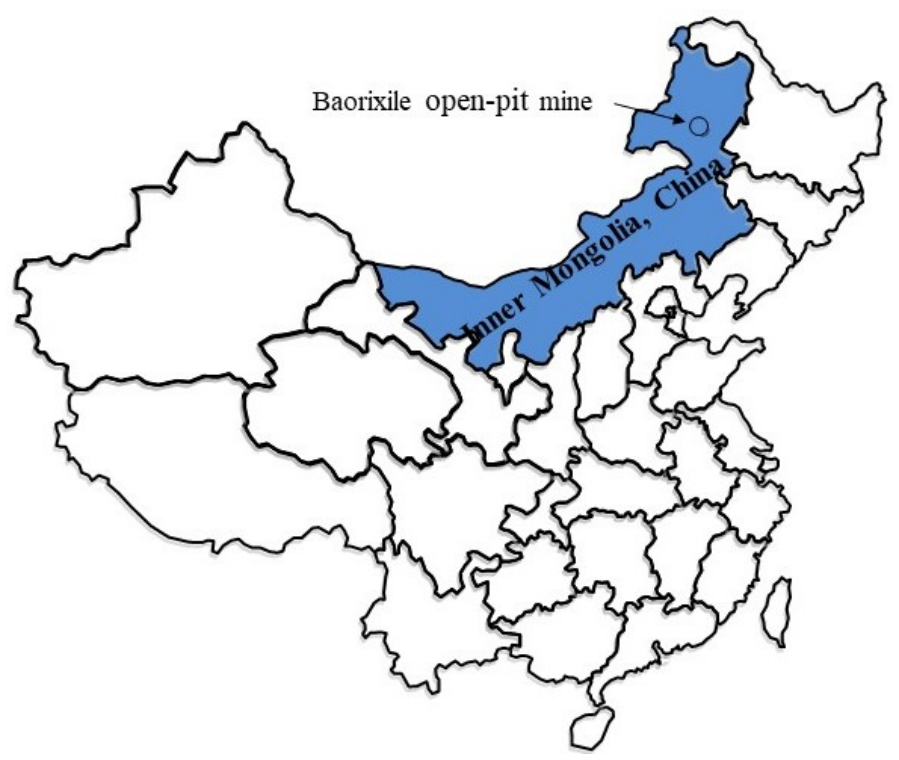

Figure 1. Location of the Baorixile open-pit mine.

Figure 2 illustrates the layout of the open-pit mine. The refuse dump is also shown with an in-situ picture of it. In the Baorixile open-pit mine, the stripped materials are transported to the inner dump, where the soil sampling was performed. The height of the inner dump is around $240 \mathrm{~m}$ (the bottom level of the dump bench is 470 and the top level of the dump bench is 710). The bench angle is $33^{\circ}$ and the length of the dump line is about $1600 \mathrm{~m}$. The total volume of rock transported to the inner dump is about 160 million cubic meters per year.

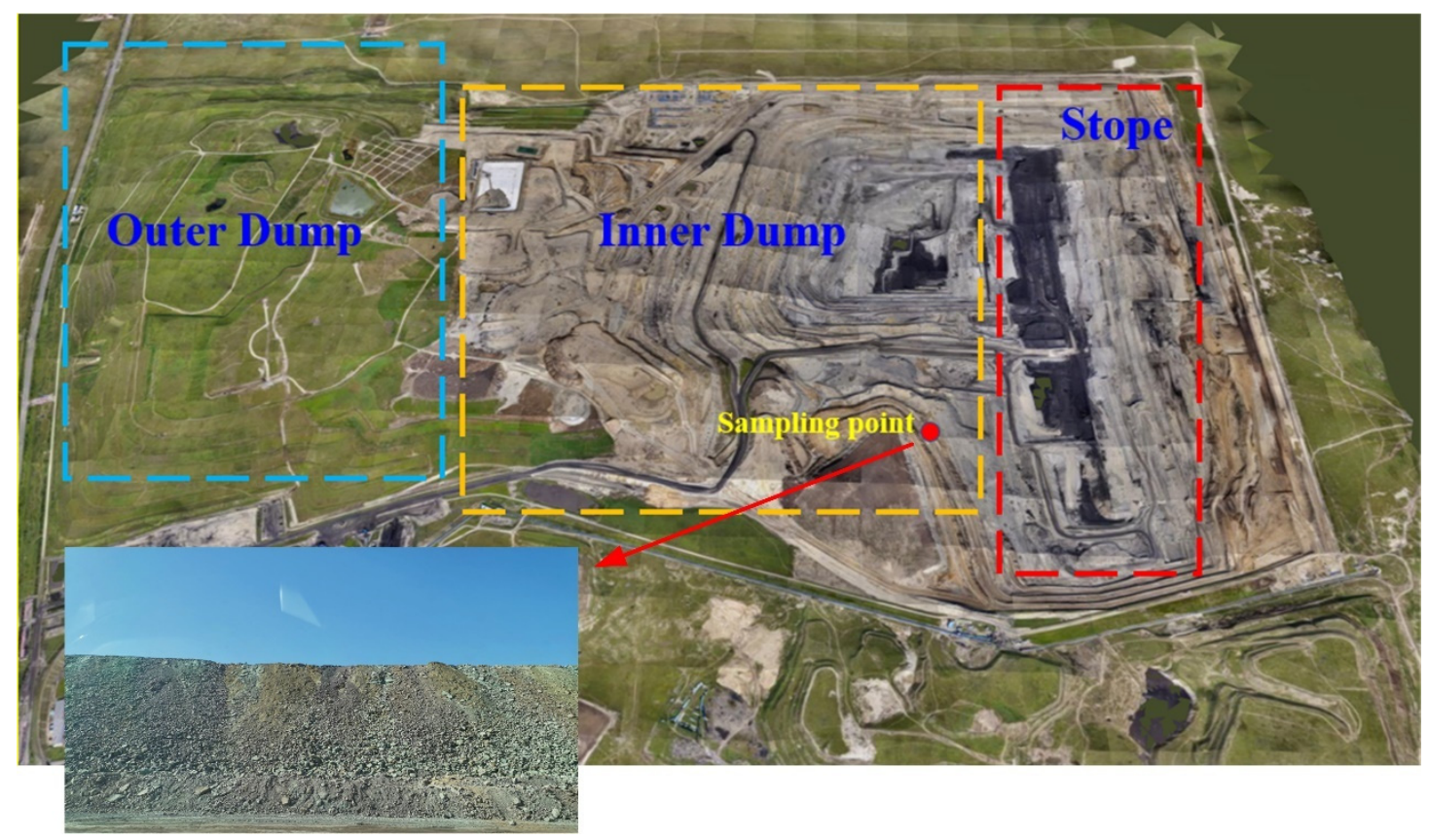

Figure 2. Layout of the Baorixile open-pit mine. 
A water pycnometer was used for bulk density measurement and a $\mathrm{pH}$ meter (Equiptronics EQ-621, Maharashtra, India) was used to measure $\mathrm{pH}$ at the suspension of 2:5 $(w / v)$, which is recommended in the literature [32,33]. A conductivity meter of the type of DDSJ 308A, China was used for the measurement of electrical conductivity. The specific surface area was measured through the $\mathrm{N}_{2}$ adsorption method using the ASAP 2460 (Micromeritics, Norcross, GA, USA) [34]. The particle size distribution was determined using a laser analyzer (BT-9300HT, Dandong, China). The mineralogical properties were characterized using X-ray powder diffraction (D8 ADVANCE, Bruker, Billerica, MA, USA) and qualified using the Rietveld method. The elemental composition was determined using $\mathrm{X}$-ray fluorescence (S8 TIGER, Bruker, Billerica, MA, USA). All materials characterization was repeated three times and Table 1 summarizes the basic physicochemical properties of soil.

Table 1. Basic soil physicochemical characteristics.

\begin{tabular}{cc}
\hline Parameter & Soil \\
\hline Bulk density $\left(\mathrm{g} / \mathrm{cm}^{3}\right)$ & $1.65 \pm 0.04$ \\
$\mathrm{pH}$ & $8.5 \pm 0.26$ \\
Specific surface area $\left(\mathrm{m}^{2} / \mathrm{g}\right)$ & $3.48 \pm 0.07$ \\
Electrical conductivity $(\mathrm{uS} / \mathrm{cm})$ & $873 \pm 50.42$ \\
$\mathrm{D}_{50}(\mu \mathrm{m})^{\mathrm{a}}$ & $36.37 \pm 0.06$ \\
$\mathrm{C}_{\mathrm{u}} \mathrm{b}$ & $17.38 \pm 0.38$ \\
$\mathrm{C}_{\mathrm{c}} \mathrm{c}$ & $0.70 \pm 0.01$ \\
$\alpha-\mathrm{SiO}_{2}$ & $64.5 \% \pm 5.7 \%$ \\
$\gamma$-Fe & $35.5 \% \pm 4.1 \%$ \\
\hline
\end{tabular}

Note: ${ }^{\mathrm{a}}$-median grain size, $\mu \mathrm{m} ;{ }^{\mathrm{b}}$-coefficient of uniformity; ${ }^{\mathrm{c}}$-coefficient of curvature. Values before \pm are average values and values after \pm are standard deviations.

Moreover, the trace element concentrations in soil were also determined. It was found that the $\mathrm{Cr}$, $\mathrm{Cd}, \mathrm{Pb}$, and As concentration in soil was $29.84 \pm 1.97 \mathrm{mg} / \mathrm{g}, 2.68 \pm 0.35 \mathrm{mg} / \mathrm{g}, 11.30 \pm 0.94 \mathrm{mg} / \mathrm{g}$, and $99.42 \pm 7.86 \mathrm{mg} / \mathrm{g}$, respectively. Compared with the GB 15618-2018 risk screening value (RSV, $250 \mathrm{mg} / \mathrm{g}$ for $\mathrm{Cr}, 0.6 \mathrm{mg} / \mathrm{g}$ for Cd, $170 \mathrm{mg} / \mathrm{g}$ for $\mathrm{Pb}$, and $25 \mathrm{mg} / \mathrm{g}$ for As), the soil from the mine site was not suitable for plant cultivation considering the environmental regulations. The authors note that the GB15618-2018 RSV is the national standard in China, above which potential risk might be encountered for crop growth [35].

\subsubsection{Soil Amendments}

The maize straw was obtained from a cropland area near the mine site. Maize straw was washed and rinsed using distilled water. Then, it was chopped and passed through a sieve with a $0.15 \mathrm{~cm}$ mesh size. To investigate the influence of maize straw, maize straw leachates (MSLs) were prepared for seed germination experiments. According to the designed concentrations of the leachates (the volume ratio of maize straw to water, from $0 \%$ to $50 \%$ with a $10 \%$ interval), a certain amount of maize straw powder (from 0 to $500 \mathrm{~mL}$ ) was soaked within $1 \mathrm{~L}$ distilled water for $24 \mathrm{~h}$. The mixture was filtered by the filter paper and the filtering was repeated three times. The prepared leachates were stored at $4{ }^{\circ} \mathrm{C}$. The prepared MSLs were used to determine the effect of MSLs (through seedling experiments) and the co-effect of MSLs + UCFA (through plant growth experiments) in the current study.

CFA was sampled from a nearby thermal power station using electrostatic precipitators. To remove impurities caused by insufficient burning, CFA samples were passed through a sieve with a $1 \mathrm{~mm}$ mesh size. Characterization of CFA was conducted in a similar way to that of the soil samples (i.e., characterization was repeated three times) and Table 2 summarizes the physicochemical properties of CFA. Moreover, it was found that the As concentration in CFA was $109.75 \pm 7.86 \mathrm{mg} / \mathrm{kg}$, which was higher than the GB 15618-2018 risk intervention value (RIV) in China. 
Table 2. Basic CFA physicochemical characteristics.

\begin{tabular}{cccc}
\hline Parameter & CFA & Parameter & CFA \\
\hline Bulk density $\left(\mathrm{g} / \mathrm{cm}^{3}\right)$ & $1.06 \pm 0.02$ & $\beta-\mathrm{SiO}_{2}$ & $9.7 \% \pm 1.05 \%$ \\
$\mathrm{pH}$ & $10.2 \pm 0.83$ & $\mathrm{Al}_{2} \mathrm{O}_{3}$ & $11.5 \% \pm 0.82 \%$ \\
Specific surface area $\left(\mathrm{m}^{2} / \mathrm{g}\right)$ & $41.28 \pm 2.19$ & $\mathrm{Si}$ & $9.23 \% \pm 0.79 \%$ \\
Electrical conductivity $(\mathrm{uS} / \mathrm{cm})$ & $820 \pm 49.15$ & $\mathrm{Al}$ & $5.45 \% \pm 0.62 \%$ \\
$\mathrm{D}_{50}(\mu \mathrm{m})^{\mathrm{a}}$ & $32.23 \pm 5.49$ & $\mathrm{Fe}$ & $1.94 \% \pm 0.15 \%$ \\
$\mathrm{C}_{\mathrm{u}} \mathrm{b}$ & $19.32 \pm 1.42$ & $\mathrm{Ca}$ & $6.11 \% \pm 0.74 \%$ \\
$\mathrm{C}_{\mathrm{c}}{ }^{\mathrm{c}}$ & $1.05 \pm 0.08$ & $\mathrm{~K}$ & $0.65 \% \pm 0.04 \%$ \\
Moganite & $73.2 \% \pm 6.19 \%$ & $\mathrm{Na}$ & $0.85 \% \pm 0.09 \%$ \\
$\mathrm{CaO}$ & $5.7 \% \pm 0.38 \%$ & $\mathrm{O}$ & $73.92 \% \pm 5.24 \%$ \\
\hline
\end{tabular}

Note: ${ }^{\mathrm{a}}$-median grain size, $\mu \mathrm{m} ;{ }^{\mathrm{b}}$-coefficient of uniformity; ${ }^{\mathrm{c}}$-coefficient of curvature. Values before \pm are average values and values after \pm are standard deviations.

\subsection{Lab Experiments}

\subsubsection{Ultrasonic Pre-Treatment of Coal Fly Ash}

In our previous study, it was shown that ultrasonic treatment of CFA could decrease the $\mathrm{pH}$ and electrical conductivity, reduce the concentration trace elements, improve the water-holding capacity and promote plant growth [35]. Thus, ultrasonic treatment was used in this work before its co-application with maize straw. Firstly, $30 \mathrm{~g}$ CFA was mixed homogeneously with $1 \mathrm{~L}$ deionized water. Then, a sonication bath of the type of SK3210HP, Kedao Ultrasonic Instrument Co., Ltd., China was employed to supply ultrasound waves to the samples.

Based on our previous results, the optimum ultrasonic treatment was chosen to be ultrasonic frequency $=28 \mathrm{kHz}$, the time interval $=15 \mathrm{~min}$, and the temperature $=31.7^{\circ} \mathrm{C}$ [35]. After the ultrasonic treatment, filtering and drying were conducted to prepare the ultrasonic pre-treated CFA (UCFA). Interested readers could refer to our previous paper for a detailed discussion about the ultrasonic treatment of CFA and its influence [35]. After the ultrasonic treatment of CFA, the $\mathrm{pH}$ was decreased to $8.48 \pm 0.58$.

\subsubsection{Seed Germination Experiments with Petri Dishes}

As indicated before, seed germination experiments were used to investigate the influence of maize straw on plant growth. Considering the engineering requirements and availability at the nearby mine site, three types of seeds were investigated, namely maize, alfalfa, and soybean. The selected seeds were surface-sterilized for 5 min using the $0.5 \% \mathrm{KMnO}_{4}$ solution. After that, they were washed 5 times with distilled water and dried at room temperature for 2 days [36].

The prepared seeds were cultivated in Petri dishes $(5 \mathrm{~cm}$ in diameter and $2 \mathrm{~cm}$ in height) with Whatman filter papers and $20 \mathrm{~mL}$ MSLs [37]; 30 seeds were sown in each Petri dish. For every $24 \mathrm{~h}$, a certain amount of MSLs was added to Petri dishes to ensure there was $20 \mathrm{~mL}$ MSLs inside the dishes. All Petri dishes were maintained at temperature $=25^{\circ} \mathrm{C}$, humidity $=40 \%$ humidity, and photoperiod $=12 \mathrm{~h} /$ day.

\subsubsection{Plant Growth Experiments}

A plant growth experiment was conducted to investigate the effect of MSLs and UCFA on physiological attributes, chlorophyll, and trace element concentration of maize plants. The plastic incubators were of the size of $260 \mathrm{~mm}$ length $\times 175 \mathrm{~mm}$ width $\times 115 \mathrm{~mm}$ height. Firstly, the soil and UCFA were homogeneously mixed at designed proportions (Table 3 ). The mixture was dried at $105^{\circ} \mathrm{C}$ for $48 \mathrm{~h}$. Then, MSLs were added and mixed before they were filled into the incubators. The filling height for each experimental scenario was $100 \mathrm{~mm}$. Finally, plant seeds were sown at the rate of 70 per incubator and watering was carried out immediately after seeding. 
Plant growth experiments were conducted at room temperature with the average temperature between 22 and $28^{\circ} \mathrm{C}$. A total of 20 days of cultivation (after sowing) was investigated, during which the physiological attributes of maize plants were recorded. The authors note that plant growth experiments on the soil were also carried out as the control experiments for comparison. Table 3 summarizes the experimental scenarios used in this study, which were determined considering the engineering requirements from the mine site.

Table 3. Scenarios for the plant growth experiments.

\begin{tabular}{cccccccc}
\hline No. & Soil (v.\%) & UCFA (v.\%) & MLSs (v.\%) & No. & Soil (v.\%) & UCFA (v.\%) & MLSs (v.\%) \\
\hline 1 & 50 & 50 & 0 & 11 & 60 & 0 & 40 \\
2 & 50 & 40 & 10 & 12 & 70 & 30 & 0 \\
3 & 50 & 30 & 20 & 13 & 70 & 20 & 10 \\
4 & 50 & 20 & 30 & 14 & 70 & 10 & 20 \\
5 & 50 & 10 & 10 & 15 & 70 & 0 & 30 \\
6 & 50 & 0 & 50 & 16 & 80 & 20 & 0 \\
7 & 60 & 40 & 0 & 17 & 80 & 10 & 10 \\
8 & 60 & 30 & 10 & 18 & 80 & 0 & 20 \\
9 & 60 & 20 & 20 & 19 & 90 & 10 & 0 \\
10 & 60 & 10 & 30 & 20 & 90 & 0 & 10 \\
\hline
\end{tabular}

The authors note there are no replicates for the seed germination experiments and plant growth experiments due to the time and resources limitations from the mine site. However, all experiments were performed in the same experimental conditions and with great caution. We know that this might cause some fluctuations in the experimental results. However, it is believed the trend is still quite convincing. Moreover, the change of different plant growth indicators with the change of MSLs/UCFA was quite consistent (see details in the discussion), which further implies the results were trustworthy. Note that the experimental results from incubators and Petri dishes were analyzed separately in the current study.

\subsubsection{Physiological Attributes of the Maize Plant}

Physiological attributes of the maize plants were detected to characterize their growth status. The germinative force (GF, \%) was calculated 3 days after sowing and the germinative rate (GR, \%) was calculated 7 days after sowing. The root length $(\mathrm{RL}, \mathrm{cm})$, sprout length $(\mathrm{SL}, \mathrm{cm})$, fresh weight per 10 sprouts (FW, g), and dried weight per 10 sprouts (DW, g) were also calculated after 20 days of cultivation. The GF and GR can be calculated as follows:

$$
\begin{aligned}
\mathrm{GF} & =\frac{N_{3 f}}{N_{a}} \\
\mathrm{GR} & =\frac{N_{a f}}{N_{a}}
\end{aligned}
$$

where $N_{3 f}$ represents the number of germinated seeds 3 days after sowing, $N_{a}$ represents the total number of seeds in each incubator, $N_{a f}$ represents the number of germinated seeds 7 days after sowing.

\subsubsection{Chlorophyll and Trace Element Concentration}

The determination of the chlorophyll was carried out using a spectrometer (INESA 756, Shanghai, China). To prepare the samples for the chlorophyll determination, $0.5 \mathrm{~g}$ fresh leaf from the maize plants was obtained and chopped. Then, the chopped leaves were ground until the leaf tissue was close to white. Leaf samples were filtered into a $25 \mathrm{~mL}$ beaker and diluted using acetone with $80 \%$ 
concentration. Absorbancy between $645 \mathrm{~nm}$ and $663 \mathrm{~nm}$ wavelength of the prepared solution was determined by the spectrometer. Finally, the chlorophyll can be calculated as follows $[38,39]$ :

$$
\text { Chlorophyll }=\frac{25 \times\left(20.3 A_{645}-8.04 A_{663}\right)}{0.5 \times 1000}
$$

where $A_{645}$ is the absorbancy at $645 \mathrm{~nm}$ wavelength and $A_{663}$ is the absorbancy at $663 \mathrm{~nm}$ wavelength.

The trace element concentrations within maize plants, including $\mathrm{Cr}, \mathrm{Zn}, \mathrm{Cu}, \mathrm{Cd}, \mathrm{Pb}$, and $\mathrm{As}$, were also determined. The inductively coupled plasma emission spectrometry method was employed and a PerkinElmer OPTIMA 8000 instrument was used [40,41].

The whole experimental procedure is illustrated in Figure 3.

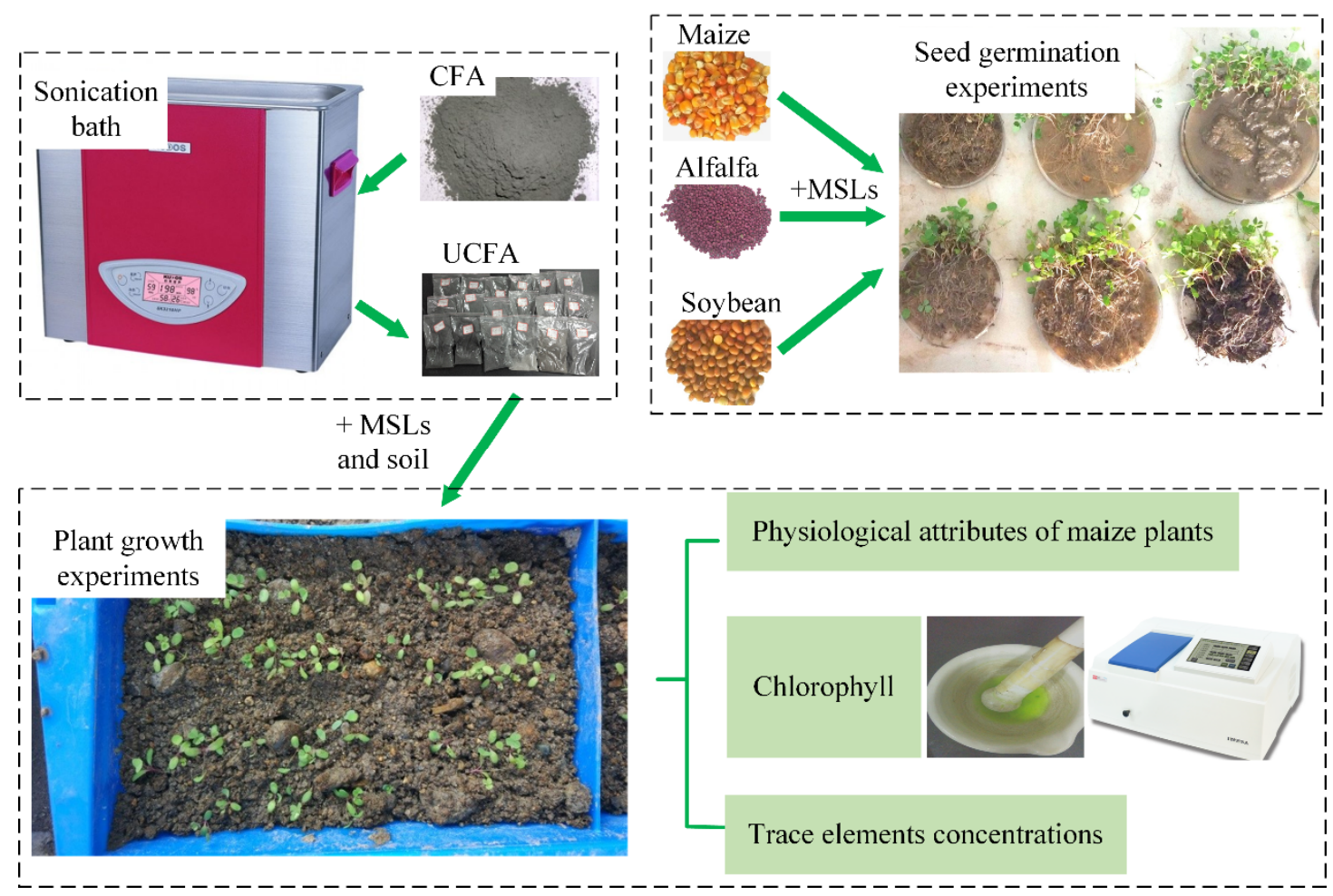

Figure 3. The experimental procedure used in this study.

\section{Results and Discussion}

\subsection{Effect of MSLs on Plant Growth}

Figure 4 illustrates the effect of MSLs concentration on GF and GR of maize, alfalfa, and soybean. Generally speaking, GF and GR increased when the MSLs concentration was increased from $0 \%$ to $20 \%$. After that, a decreasing trend was observed, though with some fluctuations, when the MSLs concentration was further increased to $50 \%$. Taking the maize seeds as an example, the GF at the $0 \%$ concentration was $66.7 \%$, which increased to $70.0 \%$ at $10 \%$ concentration and $76.7 \%$ at $20 \%$ concentration. In contrast, the GF values at $30 \%, 40 \%$, and $50 \%$ were $60.6 \%, 43.3 \%$, and $53.4 \%$, respectively. Moreover, it was found that GF and GR of alfalfa and soybean seeds were higher than that of maize seeds.

Similar results were also obtained for the influence of MSLs concentration on RL, SL, FW, DW, and chlorophyll, as indicated in Figure 5. For most cases, except the DW of maize plants, the optimum plant attributes were observed at $20 \%$ concentration. Unlike the results of GF and GR, the RL, SL, FW, DW, and chlorophyll values of maize plants were larger than those of alfalfa and soybean. 

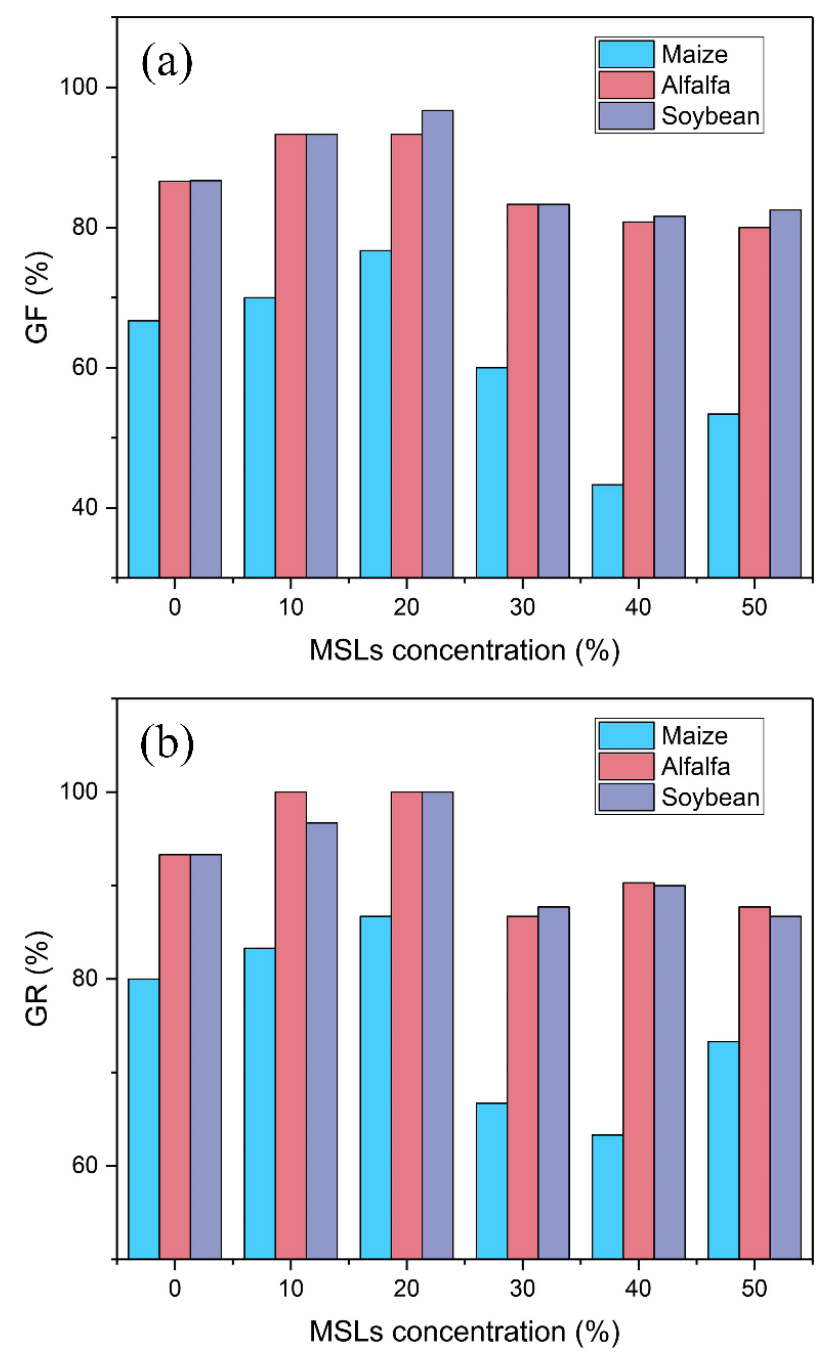

Figure 4. The influence of maize straw leachates (MSLs) concentration on: (a) germinative force (GF), and (b) germinative rate (GR).
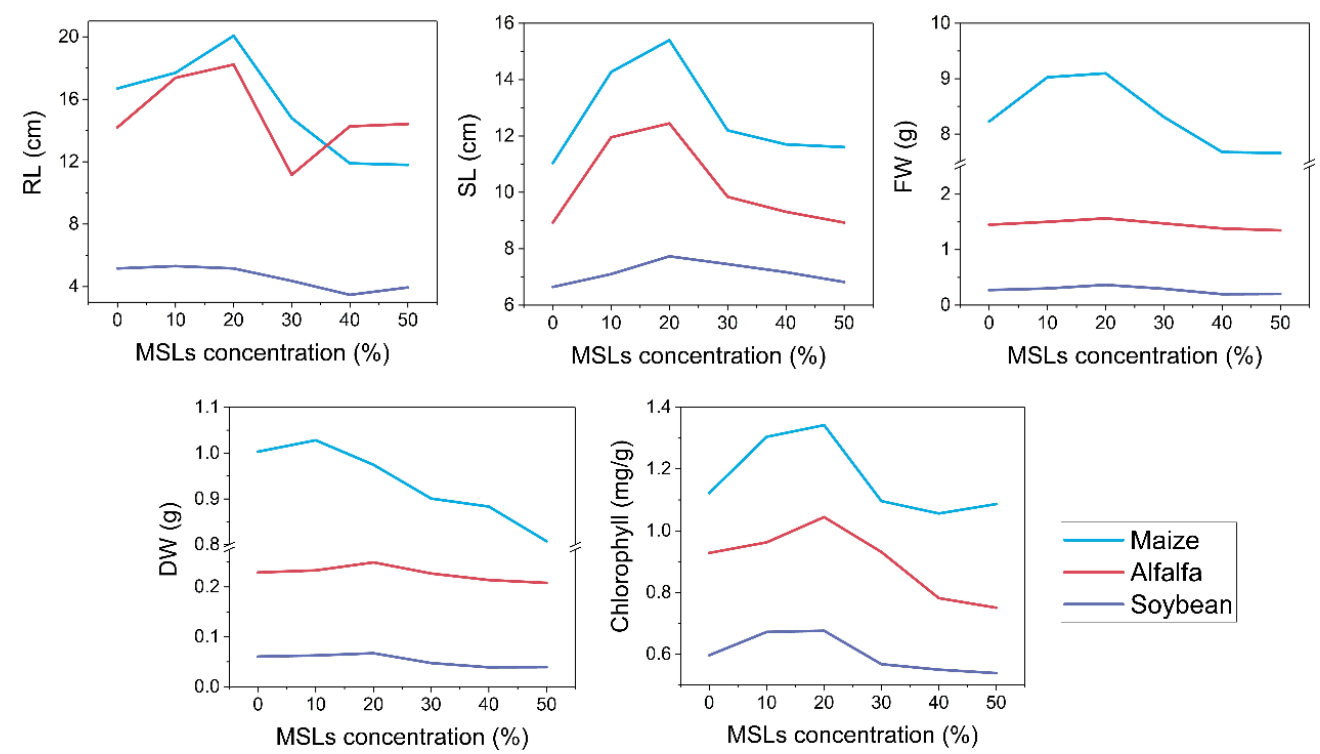

Figure 5. The influence of MSLs concentration on root length (RL), sprout length (SL), fresh weight (FW), dried weight (DW), and chlorophyll. 
Above results imply that the optimum MSLs concentration was $20 \%$ by comprehensively considering all plant characteristics. More specifically, MSLs $=20 \%$ performs the best for most cases, except for the SL of soybean (ranked 2nd) and DW of maize (ranked 3rd). Too much MSLs would slightly benefit, or even be detrimental to, plant growth. These results agree well with results in the literature, which investigated the effect of maize straw-derived biochar on winter wheat growth [31]. Considering the obtained results and engineering requirements from the mine site, maize seeds were selected for further investigation of the effect of MSLs and UCFA.

It is easily observed that the effect of MSLs on plants growth is different. In order to investigate the influence of MSLs concentration on different plants (maize, alfalfa and soybean), the variation ratio is defined as follows:

$$
\mathrm{w}=\frac{w_{\max }-w_{\min }}{w_{\min }}
$$

where $\mathrm{w}$ represents the influence ratio of MSLs on plants, $w_{\max }$ represents the maximum number of GF, GR, RL, SL, FW, DW and Chlorophyll while $w_{\min }$ represents the minimum number of GF, GR, RL, SL, FW, DW and Chlorophyll when the MSLs concentration was changed from $0 \%$ to $50 \%$.

Figure 6 shows the variation ratio of MSLs concentration on GF, GR, RL, SL, FW, DW, and Chlorophyll. In terms of GF, GR, RL, and SL, the influence of MSLs concentration on maize was more significant than other two plants. As for FW, DW and chlorophyll, the influence of MSLs concentration on soybean was more significant. The influence of MSLs concentration on alfalfa was generally around the middle among three plants.

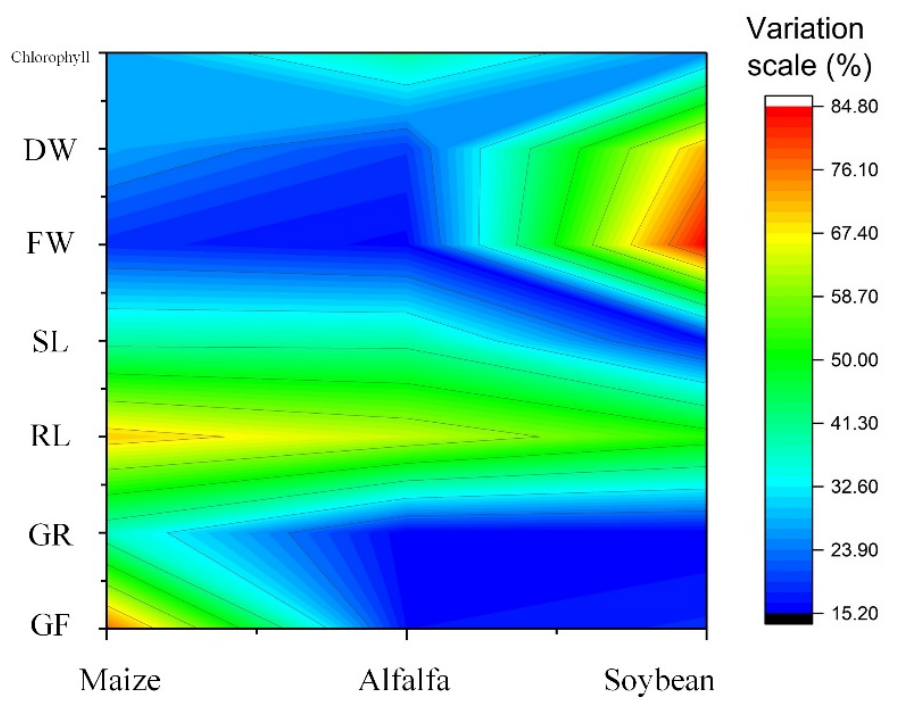

Figure 6. The variation ratio of MSLs concentration on GF, GR, RL, SL, FW, DW, and chlorophyll.

\subsection{Effect of MSLs + UCFA on Physiological Attributes of Maize Plants}

Figure 7 illustrates the effect of UCFA and soil proportions on GF and GR of maize plants. As shown, an increase in GF and GR was observed in most cases after mixing soil with MSLs and UCFA. The maize growth was suppressed in several cases, including soil:UCFA $=50: 30$, soil:UCFA $=50: 40$, soil:UCFA $=50: 50$, and soil:UCFA $=60: 40$. These results indicate too much UCFA would suppress the maize growth, whose proportion should be carefully determined for each mine site based on the soil characteristics. 

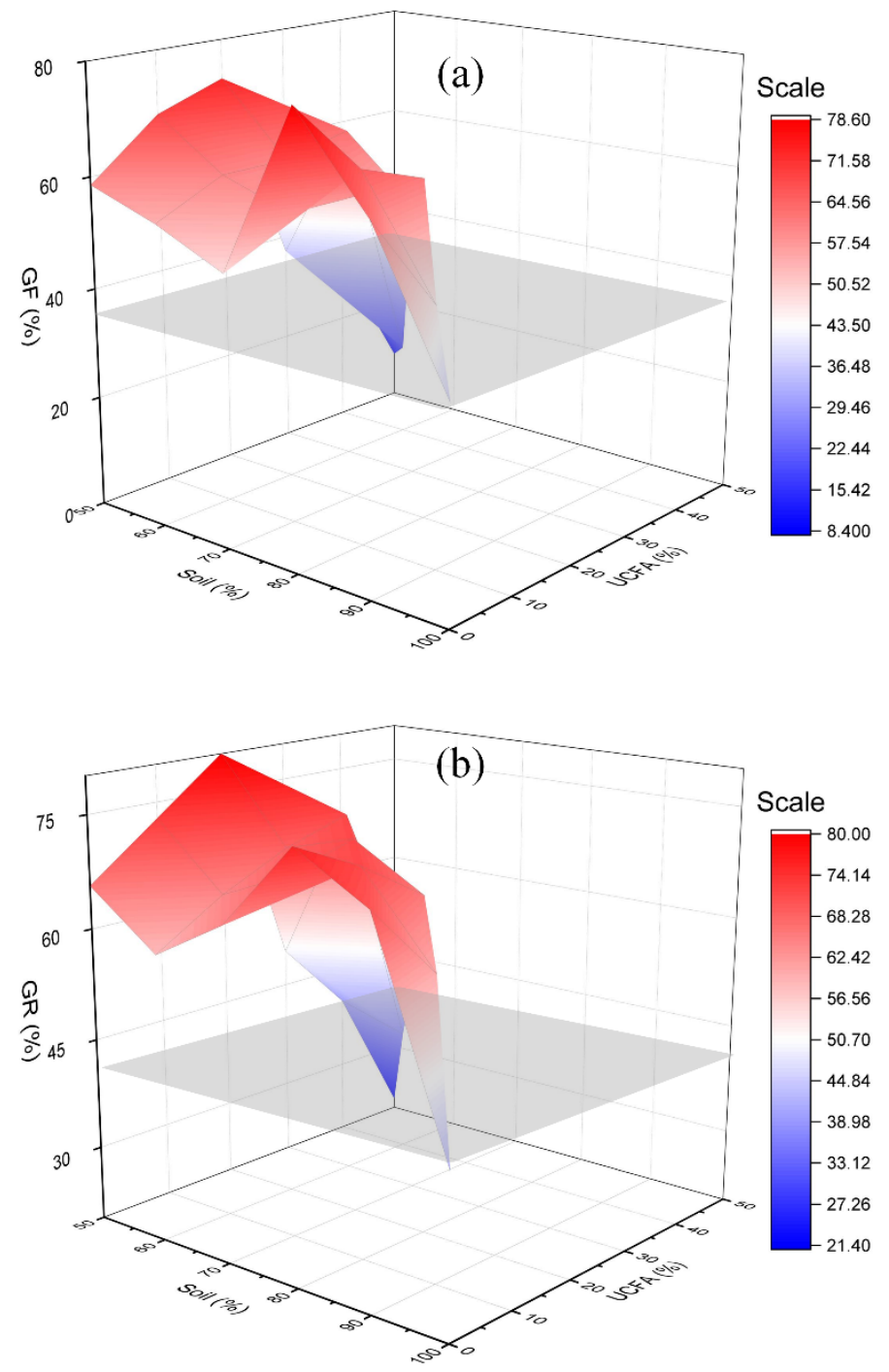

Figure 7. The influence of ultrasonically pre-treated coal fly ash (UCFA) and soil proportions on: (a) GF, and (b) GR of the maize plants. Note the gray plane represents the physiological attributes of maize plants in soil (without mixture of UCFA and MSLs).

The highest GF and GR values were observed at ratios of soil:UCFA $=80: 00$ and 50:20, respectively. In both cases, a certain amount of MSLs was added ( $20 \mathrm{v} . \%$ and $30 \mathrm{v} . \%)$ for the supply of nutrients. Generally speaking, the increase of soil from 50 v. $\%$ to 90 v.\% had relatively little influence on GF and GR. A sharp decrease was observed when the soil proportion was increased to $100 \mathrm{v} \%$. In contrast, GF and GR increased when UCFA was increased from 0 v. $\%$ to 20 v. $\%$. A further increase of UCFA proportion would lead to a decrease in GF and GR.

Figure 8 illustrates the influence of UCFA and soil proportions on RL, SL, FW, and DW of the maize plants. Generally speaking, better RL, SL, FW, and DW indicators could be observed when the UCFA proportion was less than $20 \mathrm{v} . \%$ and the soil proportion was between $70 \mathrm{v} . \%$ and $90 \mathrm{v} . \%$. These results correspond well with the results for GF and GR. In summary, the physiological attributes of maize plants indicate that the optimum UCFA proportion ranged between $10 \mathrm{v} . \%$ and $20 \mathrm{v} . \%$, the optimum soil proportion ranged between $70 \mathrm{v} . \%$ and $90 \mathrm{v} . \%$. Moreover, a small proportion of MSLs (less than $20 \mathrm{v} . \%$ for most cases) would also benefit the growth of maize plants. 

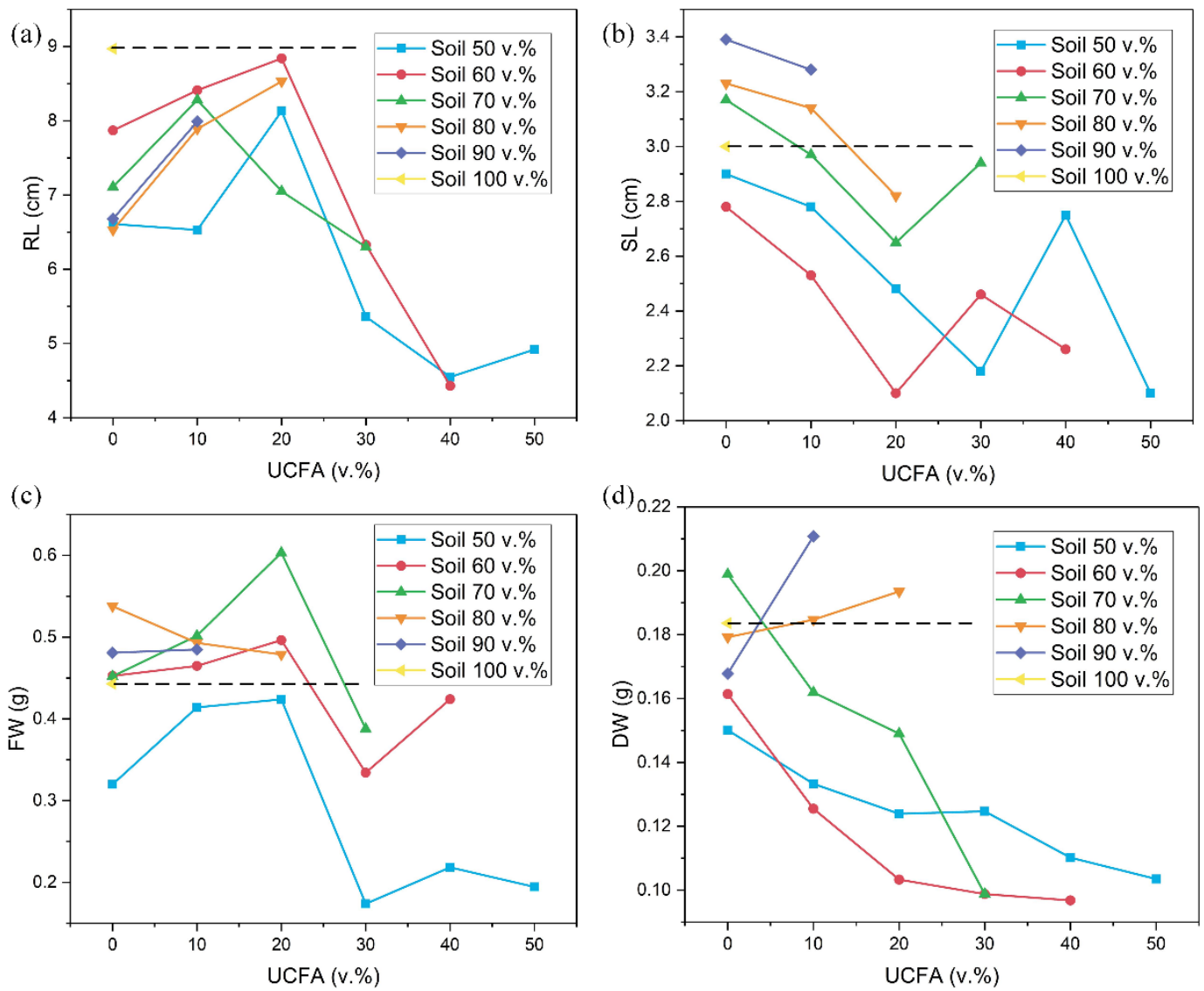

Figure 8. The influence of UCFA and soil proportions on: (a) RL, (b) SL, (c) FW, and (d) DW of the maize plants. Note the dotted line represents the physiological attributes of maize plants in soil (without mixture of UCFA and MSLs). Moreover, the remaining of (UCFA + soil) is the MSLs proportion.

\subsection{Effect of MSLs + UCFA on Chlorophyll and Trace Element Concentration of Maize Plants}

Figure 9 illustrates the influence of UCFA and soil proportions on chlorophyll of the maize plants. As shown, the chlorophyll was increased in most cases, except when soil:UCFA = 70:00, soil:UCFA $=80: 00$, and soil:UCFA $=70: 10$. Above results further confirmed the benefits of mixing soil with UCFA and MSLs. In the case of soil:UCFA $=50: 50$, the chlorophyll was doubled compared with the maize plants in soil $(2.27 \mathrm{mg} / \mathrm{g}$ in the mixture compared with $1.08 \mathrm{mg} / \mathrm{g}$ in soil). Since chlorophyll plays an essential role in absorbing light energy, converting excitation energy to reaction centers, and promoting charge separation reactions [42], an increase in chlorophyll could generally represent the improvement of the plant growth.

Figure 10 shows the trace element concentrations within the maize plants of different experimental scenarios. It can be found that the trace element concentrations with maize plants were significantly decreased with the mixture of UCFA and MSLs. In many cases, those concentrations were reduced by half, indicating an evident increase in maize growth. Taking the $\mathrm{Cr}$ concentration as an example, the $\mathrm{Cr}$ concentration within maize plants in soil was $29.84 \mathrm{mg} / \mathrm{g}$. Only two cases resulted in an increase in the $\mathrm{Cr}$ concentration $(70.53 \mathrm{mg} / \mathrm{g}$ and $45.79 \mathrm{mg} / \mathrm{g}$, respectively). Except for those two cases, the average $\mathrm{Cr}$ concentration of the remaining cases was $17.34 \mathrm{mg} / \mathrm{g}$, implying a remarkable decrease compared with the $\mathrm{Cr}$ concentration in soil.

As indicated in the literature, the trace element concentrations in CFA could be high compared with the GB 15618-2018 RSV. However, the ultrasonic treatment could reduce the trace element concentrations, enabling the UCFA to satisfy the environmental regulations. The mixture of UCFA, MSLs and soil has a "dilution effect" on the trace element concentrations, which makes maize plant growth at the mine site feasible. 


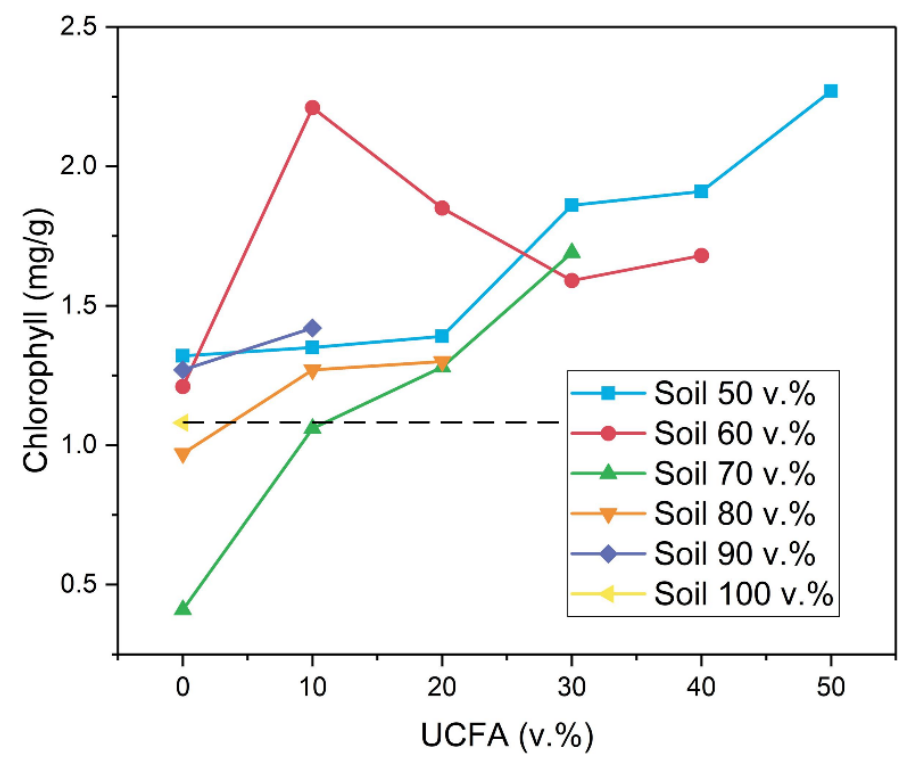

Figure 9. The influence of UCFA and soil proportions on chlorophyll of the maize plants. Note the dotted line represents the chlorophyll of maize plants in soil (without mixture of UCFA and MSLs).
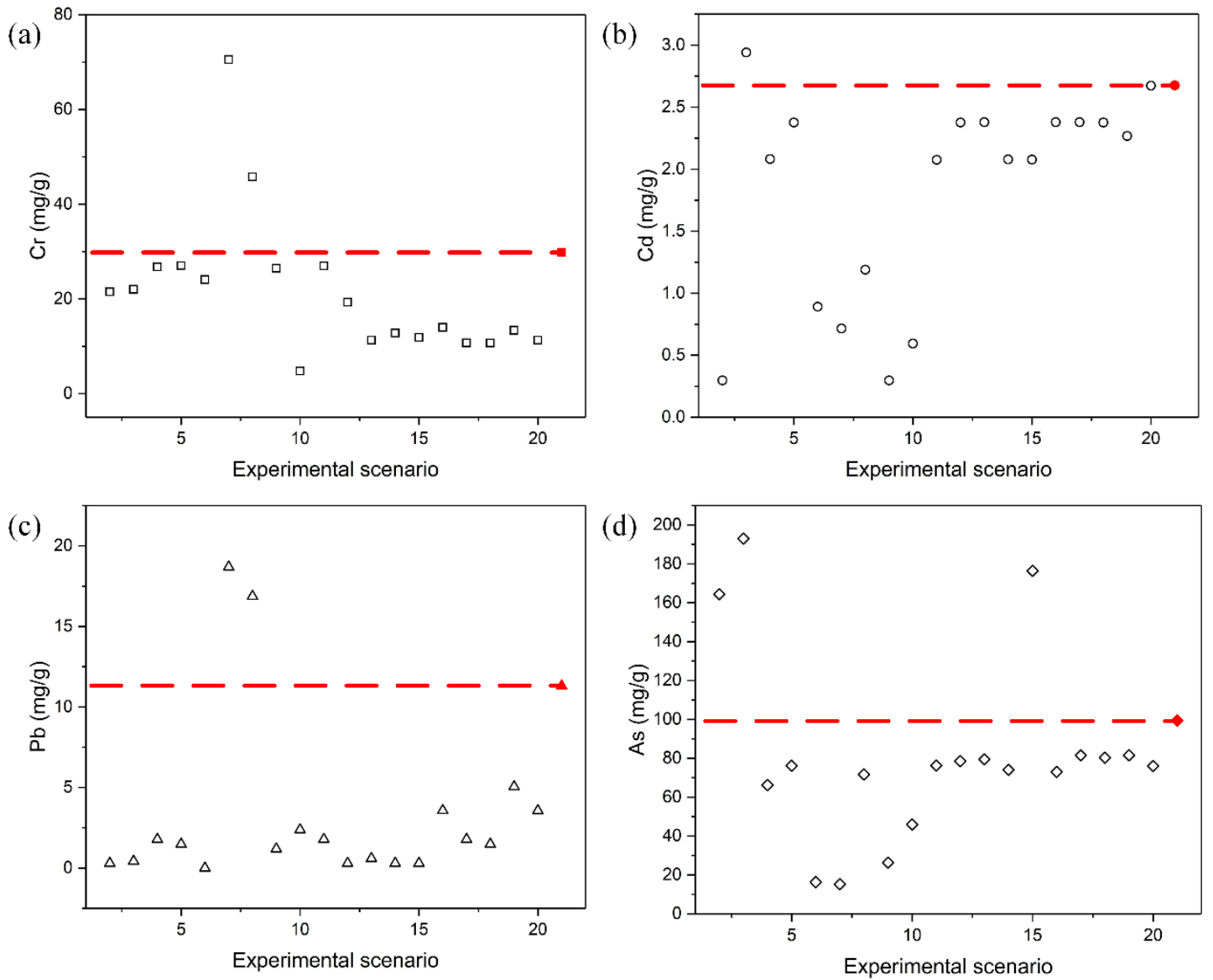

Figure 10. The trace element concentrations within the maize plants of different experimental scenarios: (a) $\mathrm{Cr}$, (b) $\mathrm{Cd}$, (c) $\mathrm{Pb}$, and (d) As. Note the dotted line represents the trace element concentrations of maize plants in soil (without mixture of UCFA and MSLs). 


\subsection{Optimum Mixture Determination and Industrial Application}

Based on the plant growth experiments, the following requirements were obtained to boost maize growth: GF and GR (UCFA proportion $\leq 40$ v. $\%$ with the optimum between 10 v. $\%$ to 20 v. $\%$ ), RL and FW (UCFA proportion $\leq 30 \mathrm{v} . \%$ with the optimum between $10 \mathrm{v} . \%$ to $20 \mathrm{v} . \%$ ), SL and DW (the smaller the UCFA proportion the better), chlorophyll (the larger the UCFA proportion the better), and trace element concentrations (should avoid several cases as indicated in Figure 9). Moreover, plant growth experiments also indicate the proportion of MSLs should be $\leq 20 \mathrm{v} . \%$ when better maize growth was expected. Figure 11 summarizes the requirements from the plant growth experiments and the determination of the optimum scenarios. As shown, the soil:UCFA:MSLs = 70:20:10 and soil:UCFA:MSLs $=60: 20: 20$ were considered to be the optimum scenarios in the current study.

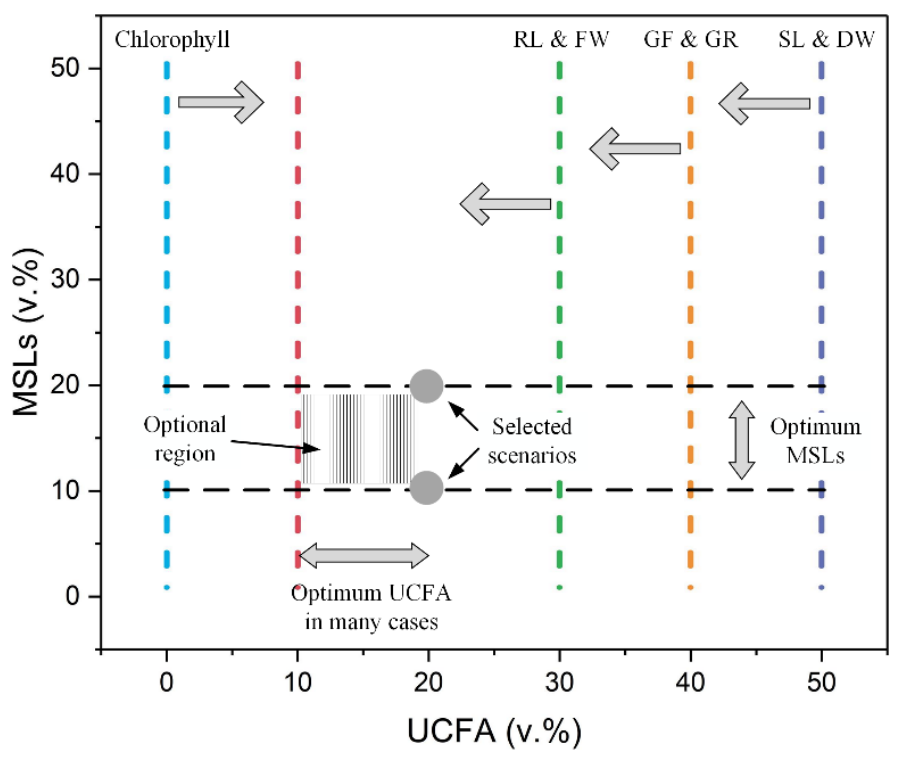

Figure 11. Optimum scenarios determination based on the plant growth experiments.

To apply the proposed rehabilitation method in the Baorixile open-pit mine, a seasonal exploitation-dump restoration strategy was developed, as illustrated in Figure 12. First-year autumn operations are characterized by stripping of the surface soil at the mine site. All stripping operations (except coal mining operations) beneath the surface soil are stopped and surface soil stripping continues until the designed level is reached. The stripped surface soil is disposed of into the inner refuse dump together with the stripped waste rock, generating a refuse dump soil (RDS). The RDS needs to be ameliorated by mixing it with UCFA and MSLs before plant restoration can begin. During the winter of the first year, the primary operation is the coal mining and occasional irrigation. The removal of soil and/or rock beneath the surface soil is mainly conducted during the second-year spring to second-year summer, while plant restoration is performed in the inner refuse dump. The proposed restoration method achieved satisfactory results during its engineering application.

As indicated before, a novel rehabilitation strategy has been proposed in the current study using a combination of refuse dump soil, UCFA, and MSLs. The proposed strategy can be used in practice to solve rehabilitation problems in refuse dumps (i.e., lack of nutrition, trace element concentration, and the disposal of CFA). Therefore, mine closure times will be improved and the recycling of CFA and maize straw can be promoted. The main drawback of the proposed strategy is the mine closure procedures will become more complex, which can be solved through designing a standard implementation method. 
(a)

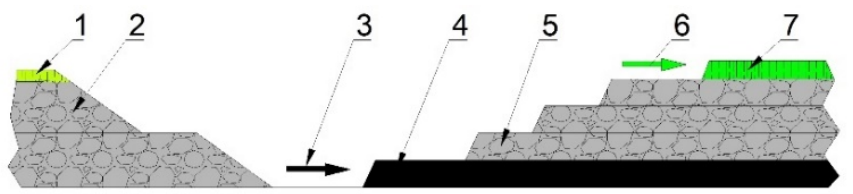

\section{Legend}

1: Region waiting

for restoration.

8

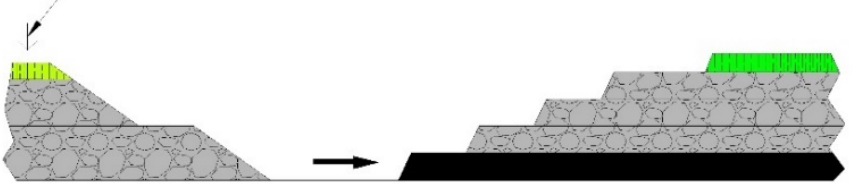

2: Inner refuse

dump.

3: Coal mining.

4: Coal seam.

5: Overlaying rock.

6: Stripping of

surface soil.

7: Original surface

soil of the mine site.

8: Irrigation in

autumn and winter.

9: Dumping of

waste rock.

10: Stripping of

rock.

(d)

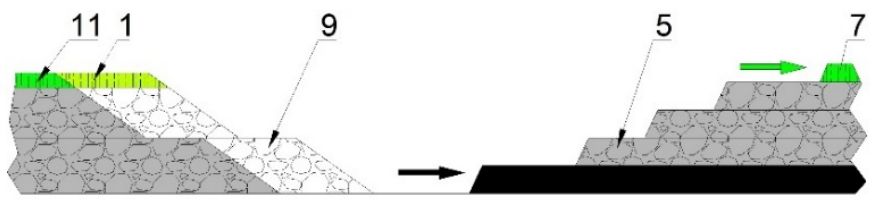

11: Restored region.

Figure 12. Seasonal exploitation dump restoration: (a) first-year autumn, (b) first-year winter, (c) secondyear spring to summer, and (d) second-year autumn.

\section{Conclusions}

In this work, a new methodology was proposed for enhanced plant restoration at the mine site. The method employs maize straw and ultrasonically pre-treated CFA for soil amelioration. The effect of MSLs concentrations on plant growth was investigated using seed germination experiments. After that, plant growth experiments were conducted to study the influence of MSLs and UCFA. The optimum mixture proportions were determined and this method was applied at the Baorixile open-pit mine. Based on the above results, the following conclusions can be drawn:

1. The MSLs concentration had a significant influence on the physiological attributes and chlorophyll of maize, alfalfa, and soybean. The increase of the MSLs concentration from $0 \%$ to $20 \%$ benefited plant growth. However, the physiological attributes and chlorophyll decreased when the MSLs concentration was further increased from $20 \%$ to $50 \%$.

2. In terms of the physiological attributes of maize plants, the mixture of MSLs + UCFA with soil would benefit maize growth in most cases. Too much UCFA was found to suppress the maize growth. The UCFA proportion should be less than $20 \mathrm{v} . \%$ and the soil proportion should be between $70 \mathrm{v} . \%$ and 90 v.\%

3. Generally speaking, the chlorophyll was increased and the trace element concentrations were decreased after mixing soil with MSLs and UCFA, which further implies the feasibility of soil amelioration using MSLs and UCFA.

4. Based on the maize growth experiments, the optimum mixture proportions were determined to be soil:UCFA:MSLs = 70:20:10 and soil:UCFA:MSLs = 60:20:20.

Author Contributions: Conceptualization, X.L. and M.Y.; methodology, X.L. and C.Q.; software, M.Y.; validation, C.Q. and W.Z.; formal analysis, X.L.; investigation, X.L.; resources, W.Z.; data curation, C.Q.; writing-original draft preparation, X.L. and C.Q.; writing-review and editing, all authors; visualization, M.Y.; supervision, W.Z.; project administration, W.Z.; funding acquisition, W.Z. All authors have read and agreed to the published version of the manuscript.

Funding: This research was funded by the Fundamental Research Funds for the Central Universities (2017XKQY097). 
Conflicts of Interest: There are no conflict of interest to declare.

\section{Nomenclature}

$\begin{array}{ll}\text { CFA } & \text { Coal fly ash } \\ \text { DW } & \text { Dried weight } \\ \text { FW } & \text { Fresh weight } \\ \text { GR } & \text { Germinative rate } \\ \text { GF } & \text { Germinative force } \\ \text { MSLs } & \text { Maize straw leachates } \\ \text { RDS } & \text { Refuse dump soil } \\ \text { RIV } & \text { Risk intervention value } \\ \text { RL } & \text { Root length } \\ \text { RSV } & \text { Risk screening value } \\ \text { SL } & \text { Sprout length } \\ \text { UCFA } & \text { Ultrasonic pre-treated coal fly ash }\end{array}$

\section{References}

1. Jambhulkar, H.P.; Kumar, M.S. Eco-restoration approach for mine spoil overburden dump through biotechnological route. Environ. Monit. Assess. 2019, 191, 772. [CrossRef]

2. Qi, C. Big data management in the mining industry. Int. J. Miner. Metall. Mater. 2020, 27, 131-139. [CrossRef]

3. Audet, P.; Arnold, S.; Lechner, A.M.; Baumgartl, T. Site-specific climate analysis elucidates revegetation challenges for post-mining landscapes in eastern Australia. Biogeosciences 2013, 10, 6545-6557. [CrossRef]

4. Doley, D.; Audet, P.; Mulligan, D.R. Examining the Australian context for post-mined land rehabilitation: Reconciling a paradigm for the development of natural and novel ecosystems among post-disturbance landscapes. Agric. Ecosyst. Environ. 2012, 163, 85-93. [CrossRef]

5. Doley, D.; Audet, P. Adopting novel ecosystems as suitable rehabilitation alternatives for former mine sites. Ecol. Process. 2013, 2, 22. [CrossRef]

6. Ngugi, M.R.; Neldner, V.J.; Doley, D.; Kusy, B.; Moore, D.; Richter, C. Soil moisture dynamics and restoration of self-sustaining native vegetation ecosystem on an open-cut coal mine. Restor. Ecol. 2015, 23, 615-624. [CrossRef]

7. Holl, K.D. Long-term vegetation recovery on reclaimed coal surface mines in the eastern USA. J. Appl. Ecol. 2002, 39, 960-970. [CrossRef]

8. Wang, Z.; Lechner, A.M.; Yang, Y.; Baumgartl, T.; Wu, J. Mapping the cumulative impacts of long-term mining disturbance and progressive rehabilitation on ecosystem services. Sci. Total Environ. 2020, 717, 137214. [CrossRef] [PubMed]

9. Deng, J.; Bai, X.; Zhou, Y.; Zhu, W.; Yin, Y. Variations of soil microbial communities accompanied by different vegetation restoration in an open-cut iron mining area. Sci. Total Environ. 2020, 704, 135243. [CrossRef]

10. Michieka, N.M. Energy and the Environment: The Relationship Between Coal Production and the Environment in China. Nat. Resour. Res. 2014, 23, 285-298. [CrossRef]

11. Talento, K.; Amado, M.; Kullberg, J.C. The Reuse of Waste Heaps from Extraction Sites: An Architectural Methodology. Sustainability 2020, 12, 6548. [CrossRef]

12. Mabey, P.T.; Li, W.; Sundufu, A.J.; Lashari, A.H. Environmental Impacts: Local Perspectives of Selected Mining Edge Communities in Sierra Leone. Sustainability 2020, 12, 5525. [CrossRef]

13. Kramer, P.A.; Zabowski, D.; Scherer, G.; Everett, R.L. Native Plant Restoration of Copper Mine Tailings: I. Substrate Effect on Growth and Nutritional Status in a Greenhouse Study. J. Environ. Qual. 2000, 29, 1762-1769. [CrossRef]

14. Bendell, L.I. Trace metal depositional patterns from an open pit mining activity as revealed by archived avian gizzard contents. Sci. Total Environ. 2011, 409, 1193-1197. [CrossRef] [PubMed]

15. Johnson, M.S.; Putwain, P.D. Restoration of native biotic communities on land disturbed by metalliferous mining. Miner. Environ. 1981, 3, 67-85. [CrossRef] 
16. Shaaban, M.; Van Zwieten, L.; Bashir, S.; Younas, A.; Núñez-Delgado, A.; Chhajro, M.A.; Kubar, K.A.; Ali, U.; Rana, M.S.; Mehmood, M.A.; et al. A concise review of biochar application to agricultural soils to improve soil conditions and fight pollution. J. Environ. Manag. 2018, 228, 429-440. [CrossRef]

17. Mushtaq, F.; Zahid, M.; Bhatti, I.A.; Nasir, S.; Hussain, T. Possible applications of coal fly ash in wastewater treatment. J. Environ. Manag. 2019, 240, 27-46. [CrossRef] [PubMed]

18. Mahedi, M.; Cetin, B.; Dayioglu, A.Y. Effect of cement incorporation on the leaching characteristics of elements from fly ash and slag treated soils. J. Environ. Manag. 2020, 253, 109720. [CrossRef]

19. Antonkiewicz, J.; Popławska, A.; Kołodziej, B.; Ciarkowska, K.; Gambuś, F.; Bryk, M.; Babula, J. Application of ash and municipal sewage sludge as macronutrient sources in sustainable plant biomass production. J. Environ. Manag. 2020, 264, 110450. [CrossRef]

20. Yao, Z.T.; Ji, X.S.; Sarker, P.K.; Tang, J.H.; Ge, L.Q.; Xia, M.S.; Xi, Y.Q. A comprehensive review on the applications of coal fly ash. Earth-Sci. Rev. 2015, 141, 105-121. [CrossRef]

21. Rivera, R.A.; Sanjuán, M.Á.; Martín, D.A. Granulated Blast-Furnace Slag and Coal Fly Ash Ternary Portland Cements Optimization. Sustainability 2020, 12, 5783. [CrossRef]

22. Ou, Y.; Ma, S.; Zhou, X.; Wang, X.; Shi, J.; Zhang, Y. The Effect of a Fly Ash-Based Soil Conditioner on Corn and Wheat Yield and Risk Analysis of Heavy Metal Contamination. Sustainability 2020, 12, 7281. [CrossRef]

23. Cho, H.; Oh, D.; Kim, K. A study on removal characteristics of heavy metals from aqueous solution by fly ash. J. Hazard. Mater. 2005, 127, 187-195. [CrossRef]

24. Ram, L.C.; Srivastava, N.K.; Jha, S.K.; Sinha, A.K.; Masto, R.E.; Selvi, V.A. Management of Lignite Fly Ash for Improving Soil Fertility and Crop Productivity. Environ. Manag. 2007, 40, 438-452. [CrossRef]

25. Pandey, V.C.; Singh, N. Impact of fly ash incorporation in soil systems. Agric. Ecosyst. Environ. 2010, 136, 16-27. [CrossRef]

26. Shaheen, S.M.; Hooda, P.S.; Tsadilas, C.D. Opportunities and challenges in the use of coal fly ash for soil improvements-A review. J. Environ. Manag. 2014, 145, 249-267. [CrossRef]

27. Belyaeva, O.N.; Haynes, R.J. Comparison of the effects of conventional organic amendments and biochar on the chemical, physical and microbial properties of coal fly ash as a plant growth medium. Environ. Earth Sci. 2012, 66, 1987-1997. [CrossRef]

28. Lian, F.; Cui, G.; Liu, Z.; Duo, L.; Zhang, G.; Xing, B. One-step synthesis of a novel N-doped microporous biochar derived from crop straws with high dye adsorption capacity. J. Environ. Manag. 2016, 176, 61-68. [CrossRef] [PubMed]

29. Shu, R.; Dang, F.; Zhong, H. Effects of incorporating differently-treated rice straw on phytoavailability of methylmercury in soil. Chemosphere 2016, 145, 457-463. [CrossRef] [PubMed]

30. Rizwan, M.S.; Imtiaz, M.; Chhajro, M.A.; Huang, G.; Fu, Q.; Zhu, J.; Aziz, O.; Hu, H. Influence of pyrolytic and non-pyrolytic rice and castor straws on the immobilization of $\mathrm{Pb}$ and $\mathrm{Cu}$ in contaminated soil. Environ. Technol. 2016, 37, 2679-2686. [CrossRef] [PubMed]

31. Shu, Y.; Zhang, Y.; Zeng, H.; Zhang, Y.; Wang, J. Effects of Cry1Ab Bt maize straw return on bacterial community of earthworm Eisenia fetida. Chemosphere 2017, 173, 1-13. [CrossRef]

32. Wu, A.; Wang, Y.; Wang, H.; Yin, S.; Miao, X. Coupled effects of cement type and water quality on the properties of cemented paste backfill. Int. J. Miner. Process. 2015, 143, 65-71. [CrossRef]

33. Parab, N.; Sinha, S.; Mishra, S. Coal fly ash amendment in acidic field: Effect on soil microbial activity and onion yield. Appl. Soil Ecol. 2015, 96, 211-216. [CrossRef]

34. Yukselen, Y.; Kaya, A. Suitability of the methylene blue test for surface area, cation exchange capacity and swell potential determination of clayey soils. Eng. Geol. 2008, 102, 38-45. [CrossRef]

35. Zhou, W.; Lu, X.; Qi, C.; Yang, M. Utilisation of ultrasonic treatment to improve the soil amelioration property of coal fly ash. J. Environ. Manag. 2020, 276, 111311. [CrossRef]

36. Zheng, Z.; Wang, Z.; Wang, X.; Liu, D. Blue Light-Triggered Chemical Reactions Underlie Phosphate Deficiency-Induced Inhibition of Root Elongation of Arabidopsis Seedlings Grown in Petri Dishes. Mol. Plant 2019, 12, 1515-1523. [CrossRef]

37. Molnárová, M.; Šmelková, M.; Fargašová, A. Assessment of the Suitability of Phytotoxkit Plastic Vertical Containers Compared with Petri Dishes for Standard Seedling Growth Tests. Bull. Environ. Contam. Toxicol. 2014, 92, 497-501. [CrossRef] 
38. Jiang, M.; Wang, J.; Rui, M.; Yang, L.; Shen, J.; Chu, H.; Song, S.; Chen, Y. OsFTIP7 determines metallic oxide nanoparticles response and tolerance by regulating auxin biosynthesis in rice. J. Hazard. Mater. 2021, 403, 123946. [CrossRef]

39. Pehlivan, N.; Gedik, K.; Eltem, R.; Terzi, E. Dynamic interactions of Trichoderma harzianum TS 143 from an old mining site in Turkey for potent metal(oid)s phytoextraction and bioenergy crop farming. J. Hazard. Mater. 2021, 403, 123609. [CrossRef]

40. Aghamirlou, H.M.; Khadem, M.; Rahmani, A.; Sadeghian, M.; Mahvi, A.H.; Akbarzadeh, A.; Nazmara, S. Heavy metals determination in honey samples using inductively coupled plasma-optical emission spectrometry. J. Environ. Health Sci. Eng. 2015, 13, 39. [CrossRef] [PubMed]

41. Francisco, B.B.A.; Rocha, A.A.; Grinberg, P.; Sturgeon, R.E.; Cassella, R.J. Determination of inorganic mercury in petroleum production water by inductively coupled plasma optical emission spectrometry following photochemical vapor generation. J. Anal. At. Spectrom. 2016, 31, 751-758. [CrossRef]

42. Chen, M. Chlorophyll Modifications and Their Spectral Extension in Oxygenic Photosynthesis. Annu. Rev. Biochem. 2014, 83, 317-340. [CrossRef]

Publisher's Note: MDPI stays neutral with regard to jurisdictional claims in published maps and institutional affiliations.

(C) 2020 by the authors. Licensee MDPI, Basel, Switzerland. This article is an open access article distributed under the terms and conditions of the Creative Commons Attribution (CC BY) license (http://creativecommons.org/licenses/by/4.0/). 